\title{
AVALIAÇÃO DA SOLDABILIDADE E DO DESEMPENHO DA UNIÃO ENTRE AÇOS APLICADOS EM ESCAPAMENTOS AUTOMOTIVOS
}

Fábio dos Santos Silva ${ }^{1 *}$ Willy Ank de Morais ${ }^{2}$

\section{Resumo}

O desenvolvimento tecnológico ocorrido nas últimas décadas tem colaborado notoriamente em desenvolvimentos na área de ciência dos materiais e particularmente nos aços, materiais estes muito empregados em aplicações automobilísticas. Nestas aplicações, os variados tipos de aços empregados necessitam de atenção especial quanto aos processos de soldagem empregados, de forma a oferecer a versatilidade e economia esperadas. Por isso, o presente estudo foi idealizado com o intuito de avaliar a utilização de arames tubulares do tipo AISI 439Ti na soldagem de escapamentos automotivos compostos de aço carbono AISI 10I8, e aço inoxidável AISI 409 ou AISI 439, em substituição ao arame de solda sólido AISI 307Si. $A$ avaliação foi embasada em resultados experimentais de análises micrograficas, fadiga, fadiga térmica, liquido penetrante e sensitização, esta última segundo a ASTM A763. Os resultados obtidos demonstraram maior eficiência do arame tubular em comparação ao arame sólido, justificando sua utilização como melhor opção como consumível para a produção do componente do sistema de escapamento automotivo avaliado.

Palavras-chave: Fadiga térmica; Corrosão intergranular; Arame tubular AISI 439Ti; Arame sólido AISI 307SI.

\section{WELDABILITY EVALUATION AND JOINT PERFORMANCE BETWEEN STEELS APPLIED FOR AUTOMOTIVE EXHAUSTS}

\begin{abstract}
The technological development occurred in the last decades has been collaborating notoriously in the development of materials science area. In the automotive market, steels are the most used materials and naturally require special attention. The welding process also stands out, since it is a permanent union process of materials and shows great versatility and economy. This study was conceived with the purpose of contributing with further clarification regarding the use of AISI 439SI tubular wires, in the welding of automotive exhausts, composed of AISI 1018 carbon steel and stainless steel AISI 409 and AISI 439 instead of AISI 307SI solid welding wire. The following tests were used to analyze test specimens produced during this study: micrographical analysis, fatigue, thermal fatigue, penetrating liquid and sensitization according to the ASTM A763 standard. The obtained results demonstrated the greater efficiency of the tubular wire compared to the solid wire, justifying its use as the best option as addition metal. With this, the recommendation of this study is the usage of tubular wire as the best addition metal option in the exhaust production.

Keywords: Thermal fatigue; Intergranular corrosion; Tubular wire AISI439Ti; Solid wire AISI 307Si.
\end{abstract}

\section{INTRODUÇÃO}

Ao longo dos anos, o aço se revelou como um dos principais materiais da indústria automotiva. Algumas das vantagens do aço nesta área são: facilidade de conformação, consistência de fornecimento, resistência à corrosão quando revestido com zinco, facilidade de união, reciclagem e boa absorção de energia em colisões [ 1$]$.
O aço é empregado em sistemas de exaustão de automóveis, parte integrante da cadeia geral de funções dos sistemas automotivos. Em princípio, os tubos do sistema de exaustão são responsáveis por unirem o coletor de exaustão, o ressonador, o silenciador e os conversores catalíticos. Esse conjunto tem como objetivo um fluxo de

'Universidade Santa Cecília - UNISANTA, Santos, SP, Brasil.

${ }^{2}$ Departamento Técnico, Willy Ank Soluções, São Vicente, SP, Brasil.

*Autor correspondente: fabiio@hotmail.com

2176-I523 @ 2020. Silva et al. Publicado pela ABM. Este é um artigo publicado em acesso aberto (Open Access) sob a licença Creative Commons Attribution, que permite uso, distribuição e reprodução em qualquer meio, sem restrições desde que o trabalho original seja corretamente citado. 
exaustão efetivo, com ruído e níveis de emissão mínimos, conforme ilustra a Figura I [2].

Os sistemas de exaustão operam a temperaturas relativamente altas, em torno de $400^{\circ}$ a $700^{\circ} \mathrm{C}$, em condições de operação tais que exigem que os materiais selecionados apresentem não apenas resistência mecânica e à fadiga adequadas, mas também excelente resistência à corrosão levando em conta a variedade de condições operacionais [3]. Neste sentido, os aços inoxidáveis ferríticos apresentam bons desempenhos em fluência, corrosão, oxidação, conformabilidade e soldabilidade comparados com outros aços inoxidáveis. A aderência entre as características dos aços inoxidáveis ferríticos com as necessidades de utilização levam a tais materiais apresentarem bom desempenho em tubos de escape dos veículos automotivos [4].

Tais componentes são unidos através de soldagem, cuja qualidade da junta, em aços inoxidáveis, está intimamente relacionada à composição do aço, além das condições térmicas associadas à soldagem e aos estados de tensão que possam estar presentes na aplicação [5]. Dentro deste cenário, os processos que empregam arame tubular permitem a realização da soldagem em posições e tipos de aços mais variados, além de propiciar propriedades mecânicas, resistência à corrosão e ao desgaste mais favoráveis no cordão de solda [6]. O resultado final do uso dos consumíveis de arame tubular costumeiramente dispensam processos de tratamento térmico pós-soldagem, o que reduz ainda mais o custo final do produto [6].

O presente estudo tem como objetivo avaliar a soldabilidade e o desempenho da união dissimilar entre aços inoxidáveis ferríticos e aços carbono em escapamentos automotivos de veículos leves, comparando-se o desempenho da adoção de dois tipos de consumíveis: arame sólido e tubular. $\bigcirc$ estudo foi realizado tendo como parâmetros ensaios de fadiga, fadiga térmica, teste de estanqueidade, liquido penetrante e corrosão intergranular (sensitização).

\section{MATERIAIS E MÉTODOS}

Neste estudo, foram confeccionados conjuntos de testes, obtidos pela soldagem entre um tubo sem chanfro de aço inoxidável e um flange, realizada na região externa dos tubos. Foram empregados dois tipos de tubos de aço inoxidável, AISI 409 e AISI 439, com 250 mm de comprimento, $45 \mathrm{~mm}$ de diâmetro e I,2 mm de espessura. Os flanges foram constituídos de aço carbono AISI I0I8, equivalente ao SAE J403 I 0 I 8 [7], e apresentavam 10 mm de espessura e área de 127,4 mm x 127,8mm, sem bisel. A Figura 2

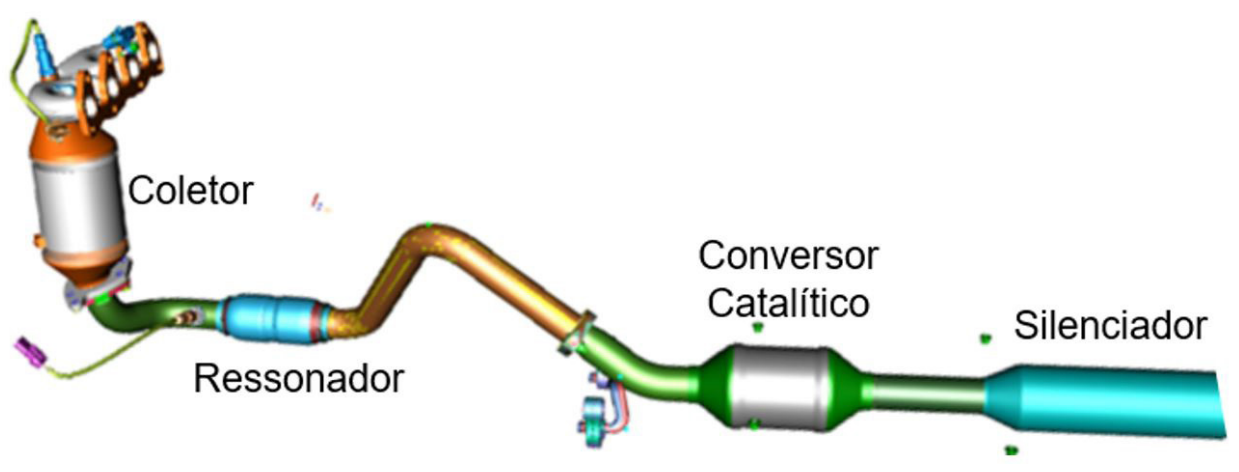

Figura I. Sistema de exaustão.
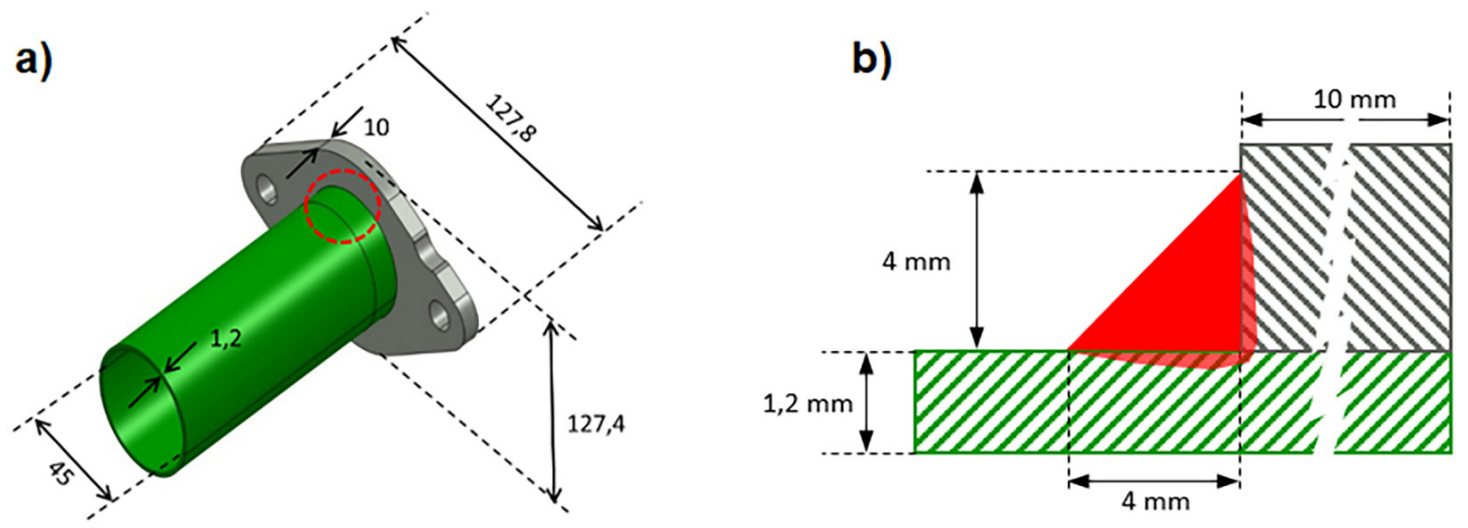

Figura 2. Conjunto de testes empregado neste estudo. a) desenho esquemático (dimensões em mm). b) o detalhe da junta soldada com as dimensões mínimas do depósito de solda. 
ilustra a geometria e as dimensões citadas enquanto que a Tabela I apresenta as composições químicas nominais dos materiais empregados.

Para confeccionar os corpos de prova, empregou-se um equipamento de soldagem da empresa Fronius, modelo Transpuls Synergic 5.000MV. O gás utilizado foi o AG I 2, de composição $98 \% \operatorname{Ar}$ e $2 \% \mathrm{CO}_{2}$. Como metal de adição, foram utilizados o consumível arame tubular AISI 439Ti, com diâmetro de I,2mm e arame sólido AISI 307Si, com diâmetro de I,2mm. Este último é atualmente empregado no processo de fabricação de escapamentos. A composição química nominal dos consumíveis está apresentada na Tabela 2.

O processo de soldagem utilizado foi GMAW, mais conhecida no meio industrial como soldagem MIG/MAG. Os arames sólidos e tubulares foram utilizados nas duas combinações de consumíveis e metal de base, ou seja, flange AISI 1018 x tubo de aço inoxidável AISI 409 e flange AISI 1018 x tubo de aço inoxidável AISI 439.

Os parâmetros de soldagem empregados neste estudo, foram parâmetros industrialmente aplicados para produção de escapamentos automotivos, e estão apresentados na Tabela 3.

Os ensaios de fadiga foram realizados conforme recomendações de uma montadora automotiva nacional, parceira deste trabalho, empregando-se uma amplitude I. $200 \mathrm{~N}$, igual em tração e compressão, assim constituindo um carregamento típico de Wöhler no qual a tensão média é nula, $\sigma_{m}=0$, e a razão entre tensões, $R=-\mathrm{I}$. $O$ carregamento foi aplicado no conjunto de testes (vide Figura 2) diretamente no tubo a uma frequência de $8 \mathrm{~Hz}$. Os ensaios foram executados em um equipamento de ensaios de fadiga, fabricado pela empresa MOOG, empregando um servo-atuador modelo G446-1024. A Figura 3 apresenta a configuração de testes empregada neste estudo.

Os ensaios de fadiga térmica foram realizados para reproduzir certas condições de trabalho existentes no escapamento automotivo. Para realizar estes testes empregou-se um queimador industrial, do tipo Duto, da empresa Holamaq. Foram executados 200 ciclos de fadiga térmica em cada corpos-conjunto (vide Figura 2). Cada ciclo envolveu a fase de aquecimento do gás até uma temperatura de $700^{\circ} \mathrm{C}$ e uma fase de resfriamento por convecção ao ar comprimido, a uma vazão de $300 \mathrm{~kg} / \mathrm{h}$, até a temperatura de $25^{\circ} \mathrm{C}$, completando um ciclo em 4,5 minutos, conforme apresentado pelo gráfico da Figura 4.

Amostras dos conjuntos testados (vide Figura 2) foram retiradas em cortes transversais para ensaios micrográficos. Os ensaios micrográficos foram realizados conforme a norma ASTM EI I2-I3 [8]. Na preparação metalográfica foram utilizados equipamentos padronizados da marca Arotec, sendo que as amostras foram lixadas e polidas, com o processo terminado ao se usar pasta de diamante com granulometria 0,25 $\mu \mathrm{m}$. Após a preparação, as amostras foram atacadas com ácido oxálico $\left(\mathrm{H}_{2} \mathrm{C}_{2} \mathrm{O}_{4}\right)$ a $10 \%$, para revelação de sua microestrutura. $A$ análise micrográfica foi realizada utilizando microscópio ótico e câmara de captura de imagem Olympus.

Para os ensaios de corrosão, as amostras foram preparadas e manuseadas de acordo com a norma ASTM A763-93 [9] com ataque eletrolítico em ácido

Tabela I. Composição química (\%) dos aços empregados nos tubos e flange: limites máximos (indicados) e valores médios

\begin{tabular}{cccccccccc}
\hline Material & $\% \mathbf{C}$ & $\%$ Mn & \%Si & \%P & \%S & \%Cr & \%Ni & \%Mo & $\%$ Ti \\
\hline AISI I0I8 & 0,18 & 0,75 & - & $\leq 0,04$ & $\leq 0,05$ & - & - & - & - \\
AISI 409 & $\leq 0,03$ & $\leq 0,75$ & $\leq 1,00$ & $\leq 0,04$ & $\leq 0,02$ & 11,00 & $\leq 0,50$ & - & 0,30 \\
AISI 439 & $\leq 0,07$ & $\leq 1,00$ & $\leq 1,00$ & $\leq 0,04$ & $\leq 0,03$ & 18,00 & $\leq 0,50$ & - & 0,30 \\
\hline
\end{tabular}

Tabela 2. Composição química (\%) dos consumíveis empregados: valores médios

\begin{tabular}{ccccccc}
\hline Material & \%C & \%Mn & \%Si & \%Cr & \%Ni & \%Ti \\
\hline AISI 307Si & 0,08 & 7,00 & 0,90 & 18,00 & 8,0 & - \\
AISI 439Ti & 0,02 & 0,50 & 0,50 & 17,50 & - & 0,50 \\
\hline
\end{tabular}

Tabela 3. Parâmetros de soldagem empregados neste estudo

\begin{tabular}{lccc}
\hline \multicolumn{1}{c}{ PARÂMETROS } & TUBULAR (EXTERNO) & TUBULAR (INTERNO) & $\begin{array}{c}\text { SÓLIDO (INTERNO E } \\
\text { EXTERNO) }\end{array}$ \\
\hline Programa & 10 & 10 & 9 \\
& $\mathrm{CrNi}=>18-8-6$ & $\mathrm{CrNi}=>18-8-6$ & $\mathrm{CrNi}=>18-8-6$ \\
Arame & $\mathrm{I}, 2 \mathrm{~mm}=>\mathrm{MC} 439 \mathrm{Ti}$ & $\mathrm{I}, 2 \mathrm{~mm}=>\mathrm{MC} 439 \mathrm{Ti}$ & $\mathrm{I}, 0 \mathrm{~mm}=>307 \mathrm{Si}$ \\
Corrente $(\mathrm{A})$ & $325 \mathrm{~A}$ & $295 \mathrm{~A}$ & $202 \mathrm{~A}$ \\
Tensão $(\mathrm{V})$ & 27,3 & $21,3 \mathrm{~V}$ & $27,3 \mathrm{~V}$ \\
Indutância & -5 & -5 & -5 \\
Comprimento do Arco & -18 & -15 & -18 \\
Velocidade $(\mathrm{mm} / \mathrm{s})$ & 25 & 25 & 25 \\
Gás & $\mathrm{AGI}$ & $\mathrm{AG} / 2$ & $\mathrm{AGI2}$ \\
\hline
\end{tabular}


oxálico $10 \%$, cuja composição é I0g de Ácido Oxálico e $10 \mathrm{ml} \mathrm{H}_{2} \mathrm{O}\left(\mathrm{H}_{2} \mathrm{C}_{2} \mathrm{O}_{4} \cdot 2 \mathrm{H}_{2} \mathrm{O}\right)$ com o objetivo de se caracterizar a suscetibilidade a corrosão intergranular.

\section{RESULTADOS}

Os resultados obtidos na avaliação de penetração da solda, para os corpos de prova produzidos com o arame tubular, atenderam o especificado pela norma da montadora parceira do trabalho. A Tabela 4 apresenta os resultados obtidos e os limites considerados aceitáveis pela montadora. Tais valores foram determinados pela análise de imagem das micrografias, conforme ilustrado na Figura 5.

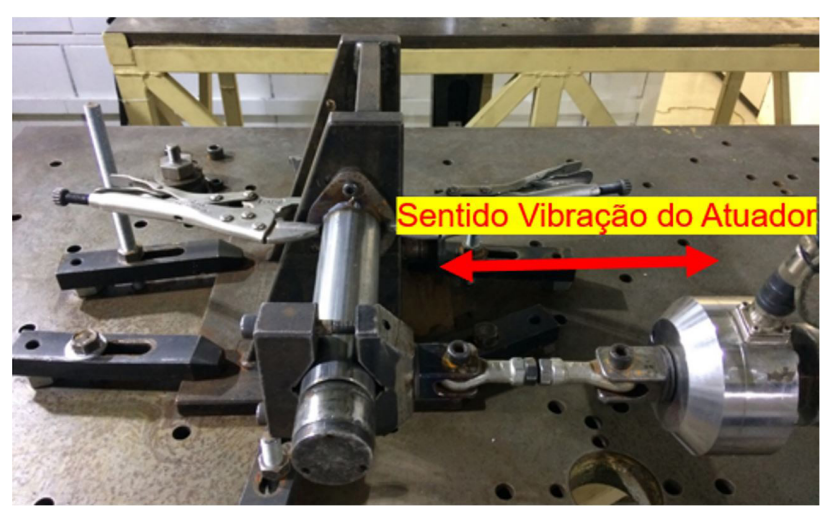

Figura 3. Configuração do ensaio de fadiga.

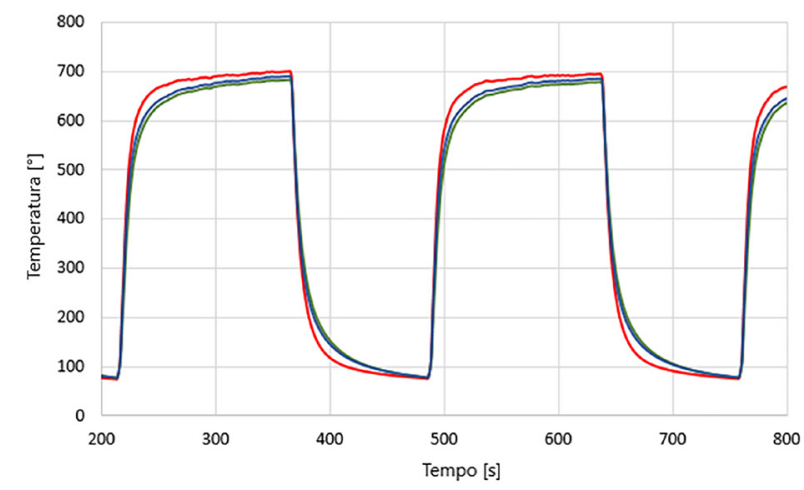

Figura 4. Gráfico representativo dos ciclos de temperatura versus tempo adotados nos ensaios de fadiga térmica.
Por outro lado, os resultados da avaliação de penetração da solda para os corpos de prova produzidos com o arame sólido, tiveram todas as suas amostras rejeitadas, devido ao não atendimento de algum dos parâmetros de penetração, conforme apresentado pela Tabela 5.

A Tabela 6 apresenta, para os conjuntos testados (vide Figura 2) constituídos de tubo de aço inoxidável 409 e 439, uma comparação entre o número de ciclos totais obtidos em condições de fadiga, quanto tais conjuntos foram soldados com arame tubular e arame sólido. Neste caso, verificou-se uma tendência similar à verificada na caracterização da penetração. A utilização do arame tubular levou a um incremento médio de longevidade (resistência) à fadiga em torno de I I 0\%, ou seja, duplicando a longevidade do componente, em relação ao desempenho obtido para o arame sólido.

Os resultados dos ensaios de fadiga térmica, após a realização de 200 ciclos (vide Figura 4) estão apresentados na Tabela 7. Os dados apontam para uma perda de longevidade média de 15\% (de 125 para 106 mil ciclos), além de uma dispersão $54 \%$ maior (de 36 para 55 mil ciclos) em comparação com os resultados obtidos no teste de fadiga aplicado nos corpos de prova sem a ciclagem térmica. $O$ destaque foi para os conjuntos de aço inoxidável AISI 409, os quais apresentaram uma diferença de quase $200 \%$ entre os resultados obtidos nos conjuntos fabricados com arame sólido ( 54 mil ciclos) em relação aos fabricados com arame tubular ( 150 mil ciclos).

Os resultados obtidos e apresentados na Tabela $6 \mathrm{e}$ Tabela 7 estão apresentados nos gráficos de distribuição de probabilidades da Figura 6. Pode-se observar as tendências descritas anteriormente, especialmente a maior dispersão obtida nos dados após a submissão dos conjuntos de teste aos 200 ciclos de fadiga térmica.

Os ensaios de corrosão intergranular apresentaram resultados distintos entre a utilização dos tubos de aço inoxidável AISI 409 e 439. Todas as amostras de tubo de aço inoxidável AISI 409 foram aprovadas. Por outro lado, todas as amostras de tubos de aço inoxidável AISI 439, que possui teores médios de carbono e cromo maiores (vide Tabela I), apresentaram corrosão intergranular.

Todas as amostras foram aprovadas no ensaio de líquido penetrante, bem como no de estanqueidade, dado o fato que não foram encontrados defeitos na superfície dos corpos de prova e vazamentos durante os ensaios.

Tabela 4. Resultados obtidos da avaliação na penetração da solda empregando consumível de arame tubular e comparação com os limites especificados pela montadora parceira deste trabalho

\begin{tabular}{lccccc}
\hline & $\begin{array}{c}\text { Limites aceitáveis } \\
\text { (ref. Montadora) }\end{array}$ & $\begin{array}{c}\text { Tubo 409 } \\
\text { Arame Tubular } \\
(\mathbf{m m})\end{array}$ & $\begin{array}{c}\text { Tubo 409 } \\
\text { Arame Tubular } \\
(\mathbf{m m})\end{array}$ & $\begin{array}{c}\text { Tubo 439 } \\
\text { Arame Tubular } \\
(\mathbf{m m})\end{array}$ & $\begin{array}{c}\text { Tubo 439 } \\
\text { Arame Tubular } \\
(\mathbf{m m})\end{array}$ \\
\hline Garganta $\geq$ & $\mathrm{I}, 04$ & 3,58 & 3,45 & 3,58 & 3,79 \\
Flange $\geq$ & 1,34 & 5,16 & 4,72 & 3,71 & 4,66 \\
Tubo $\geq$ & 1,34 & 4,79 & 4,10 & 5,94 & $4,5 \mathrm{I}$ \\
Penetração Flange $\geq$ & 0,15 & 0,35 & 1,05 & 1,21 & 2,08 \\
Penetração Tubo $\geq$ & 0,15 & 0,17 & 1,22 & 1,52 & 0,64 \\
\hline
\end{tabular}




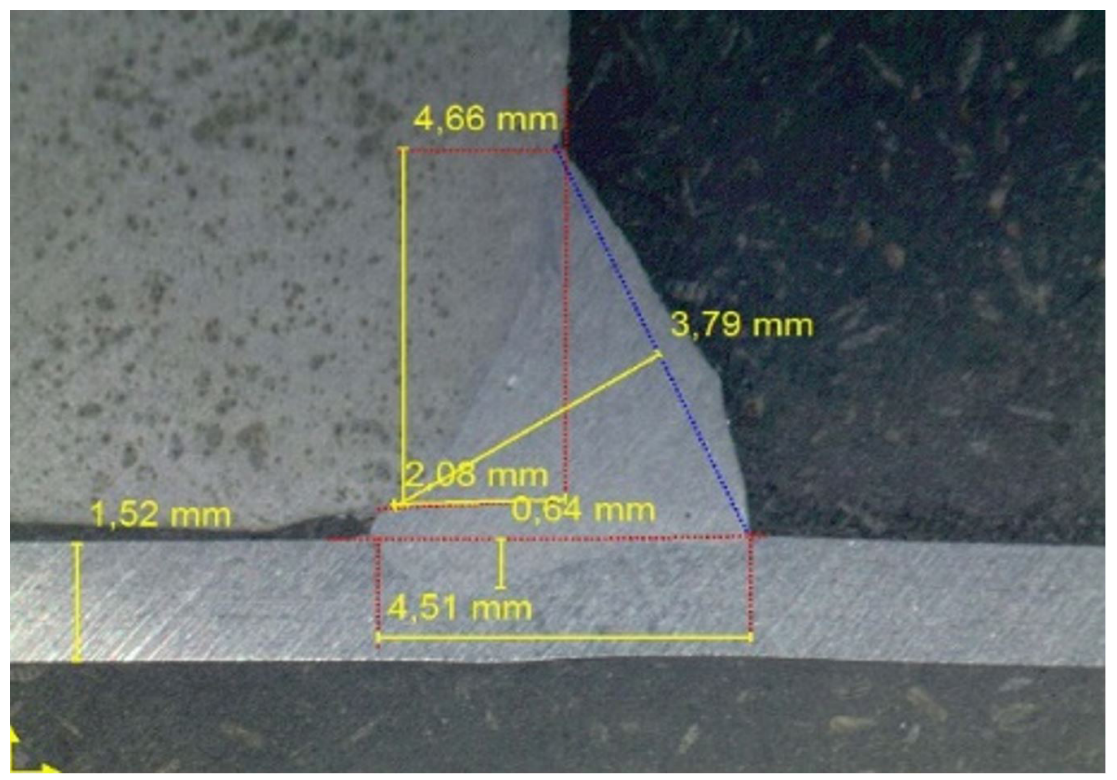

Figura 5. Exemplo da área solda entre o tubo e o flange de um dos conjuntos de testes estuados, bem como seus respectivos resultados de penetração de solda.

Tabela 5. Resultados obtidos da avaliação na penetração da solda empregando consumível de arame sólido e comparação com os limites de montadora parceira deste trabalho

\begin{tabular}{lccccc}
\hline & $\begin{array}{c}\text { Limites aceitáveis } \\
\text { (ref. Montadora) }\end{array}$ & $\begin{array}{c}\text { Tubo 409 } \\
\text { Arame Sólido } \\
(\mathbf{m m})\end{array}$ & $\begin{array}{c}\text { Tubo 409 } \\
\text { Arame Sólido } \\
(\mathbf{m m})\end{array}$ & $\begin{array}{c}\text { Tubo 439 } \\
\text { Arame Sólido } \\
(\mathbf{m m})\end{array}$ & $\begin{array}{c}\text { Tubo 439 } \\
\text { Arame Sólido } \\
(\mathbf{m m})\end{array}$ \\
\hline Garganta $\geq$ & $\mathrm{I}, 04$ & 4,50 & 4,50 & 3,47 & 3,58 \\
Flange $\geq$ & 1,33 & $\mathbf{I , 2 7}$ & 1,41 & 2,93 & 4,36 \\
Tubo $\geq$ & 1,33 & 1,45 & 0,00 & 0,00 & 0,00 \\
Penetração Flange $\geq$ & 0,15 & 0,29 & 0,32 & 0,29 & 0,40 \\
Penetração Tubo $\geq$ & 0,15 & $\mathbf{0 , 1 2}$ & $\mathbf{0 , 0 0}$ & $\mathbf{0 , 0 0}$ & $\mathbf{0 , 0 0}$ \\
\hline
\end{tabular}

Tabela 6. Número máximo de ciclos em fadiga obtidos para os conjuntos testados (vide Figure 2) constituídos de tubos de aço inoxidável 409 e 439 com flange de aço carbono AISI I0I8

\begin{tabular}{|c|c|c|c|c|c|c|c|}
\hline \multirow[t]{2}{*}{ Amostra } & \multirow[t]{2}{*}{ Aço do tubo } & \multicolumn{2}{|c|}{$\begin{array}{l}\text { Número de ciclos obtidos } \\
\text { com arame }\end{array}$} & \multirow[t]{2}{*}{ Amostra } & \multirow[t]{2}{*}{ Aço do tubo } & \multicolumn{2}{|c|}{$\begin{array}{c}\text { Número de ciclos obtidos } \\
\text { com arame }\end{array}$} \\
\hline & & Sólido & Tubular & & & Sólido & Tubo 439 \\
\hline I & AISI 409 & 92.284 & $|48.03|$ & 5 & AISI 439 & 71.683 & 148.372 \\
\hline 2 & & 100.335 & 189.325 & 6 & & 108.445 & 271.799 \\
\hline 3 & & 42.883 & $1|2.62|$ & 7 & & 108.088 & 209.488 \\
\hline 4 & & 53.956 & | 49.767 & 8 & & 74.889 & $|32.20|$ \\
\hline Média & & 72.365 & I49.936 & Média & & 90.779 & 190.465 \\
\hline Desvio & & 28.209 & 31.345 & Desvio & & 20.239 & 63.623 \\
\hline
\end{tabular}

Tabela 7. Número máximo de ciclos em fadiga obtidos, após a execução de 200 ciclos de carregamentos térmicos (vide Figure 4), para os conjuntos testados (vide Figure 2) constituídos de tubos de aço inoxidável 409 e 439 com flange de aço carbono AISI I0I8

\begin{tabular}{|c|c|c|c|c|c|c|c|}
\hline \multirow[t]{2}{*}{ Amostra } & \multirow[t]{2}{*}{ Aço do tubo } & \multicolumn{2}{|c|}{$\begin{array}{c}\text { Número de ciclos obtidos } \\
\text { com arame }\end{array}$} & \multirow[t]{2}{*}{ Amostra } & \multirow[t]{2}{*}{ Aço do tubo } & \multicolumn{2}{|c|}{$\begin{array}{c}\text { Número de ciclos obtidos } \\
\text { com arame }\end{array}$} \\
\hline & & Sólido & Tubular & & & Sólido & Tubo 439 \\
\hline 9 & AISI 409 & 35.068 & 163.231 & 13 & AISI 439 & 52.797 & 109.597 \\
\hline 10 & & 34.735 & 122.979 & 14 & & 92.271 & 280.182 \\
\hline 11 & & 115.008 & 213.489 & 15 & & 130.248 & 77.034 \\
\hline 12 & & 30.391 & 99.552 & 16 & & 50.566 & 100.290 \\
\hline Média & & 53.801 & 149.813 & Média & & 81.471 & 141.776 \\
\hline Desvio & & $40.86 I$ & 49.936 & Desvio & & $37.74 I$ & 93.282 \\
\hline
\end{tabular}




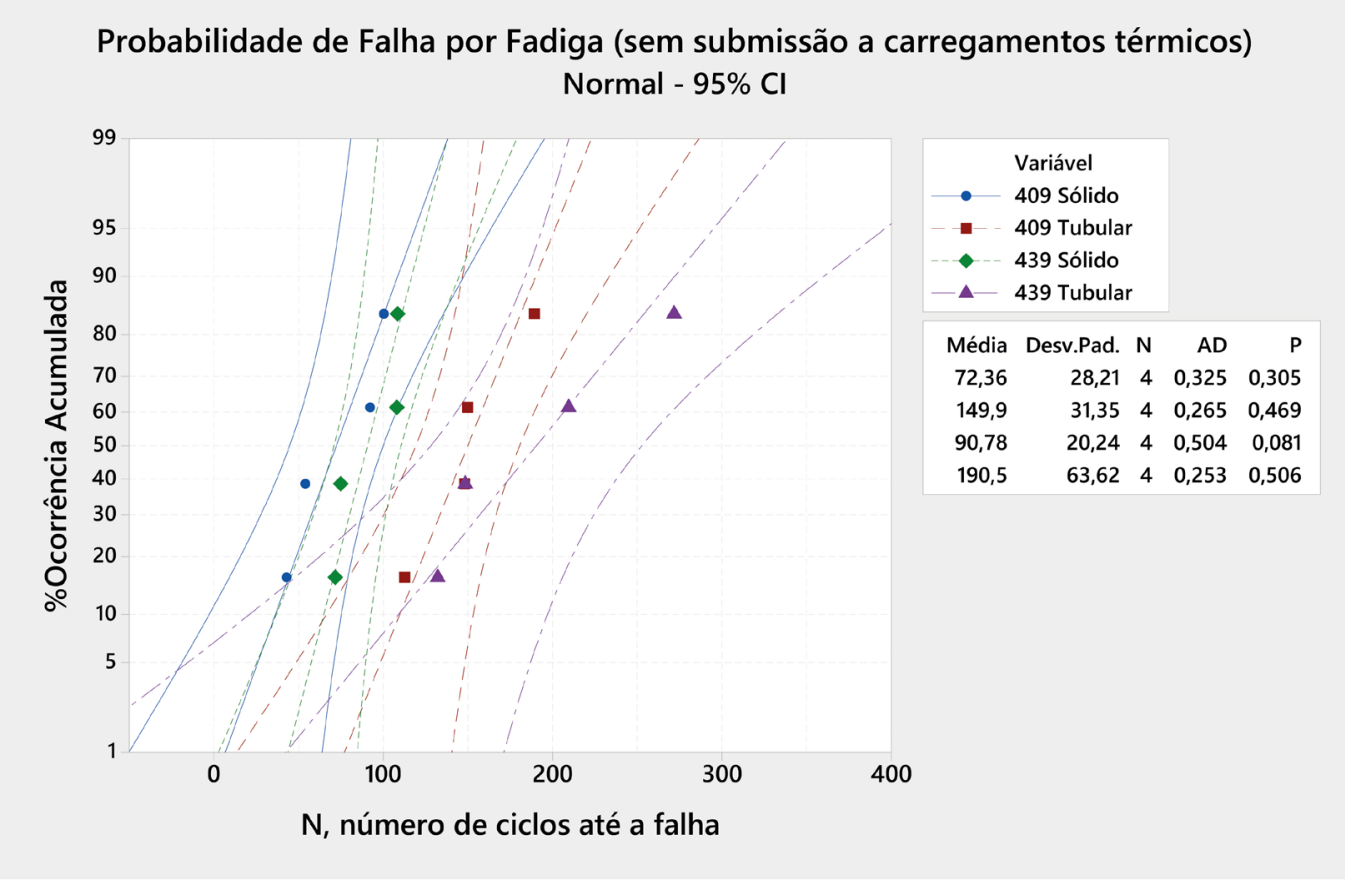

(a)

\section{Probabilidade de Falha por Fadiga (com submissão a carregamentos térmicos)} Normal $-95 \% \mathrm{Cl}$

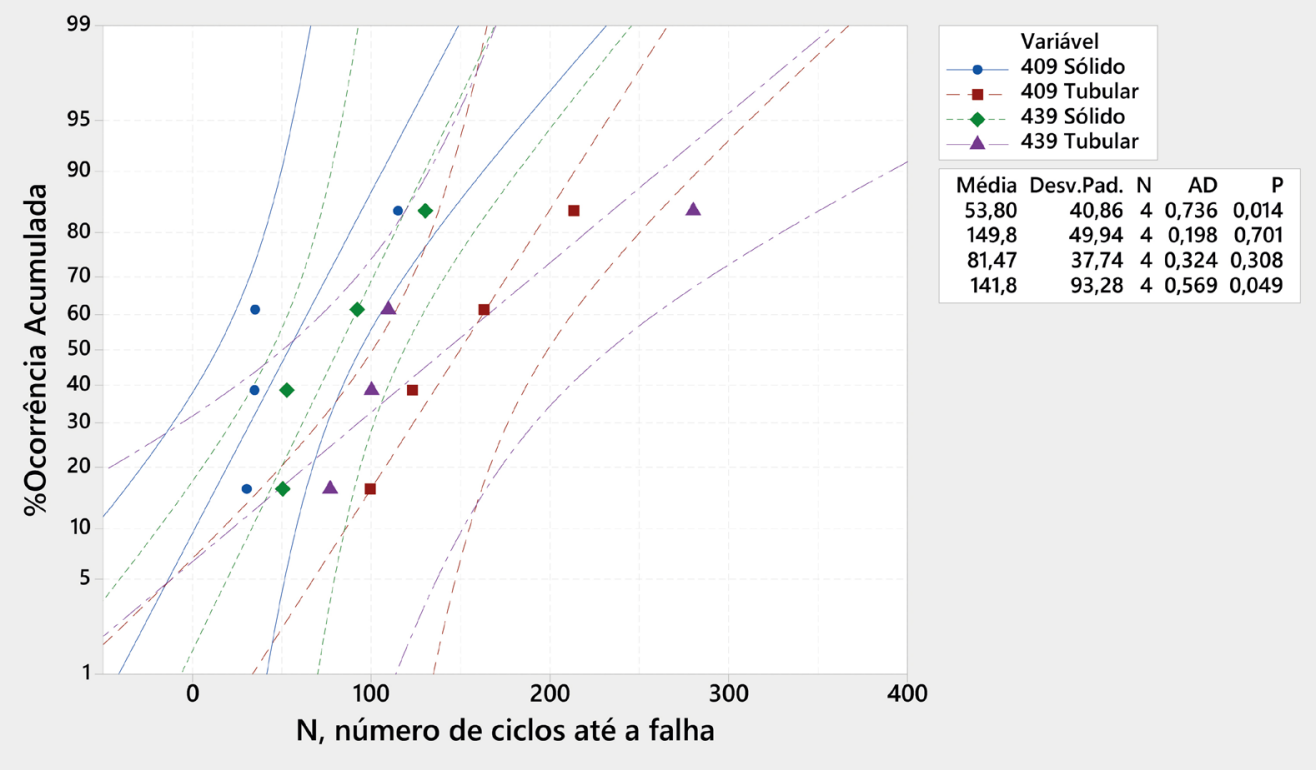

Figura 6. Gráficos de probabilidade com os dados obtidos dos ensaios de fadiga (número de ciclos antes da falha). (a) Sem submissão dos conjuntos testados à fadiga térmica; (b) Após fadiga térmica.

\section{DISCUSSÃO}

A tecnologia da soldagem vem evoluindo de maneira em que os processos e metais de adição estão se tornando cada vez mais adequados e produtivos. Neste caso, o arame tubular AISI 439Ti apresenta características metalúrgicas e processuais bastante vantajosas e bem reconhecidas na literatura [10]. Tais características foram observadas neste trabalho. Além disso, outro fator vantajoso, que não citado anteriormente, foi a velocidade de soldagem de consumível que é mais rápida em comparação com o arame sólido.

A literatura [2], aponta que, em condições normais de operação do escapamento, as amostras soldadas com tubo de aço inoxidável AISI 409 utilizando o metal de adição 
arame tubular, apresentaram melhores resultados em relação a fadiga quando comparado com as outras condições de soldagem. Os melhores resultados utilizando $o$ arame tubular AISI 439Ti, justifica-se, pois conforme Rabbi [I I], o elemento titânio no aço AISI 439Ti promove refino de grão, - que ajuda no ganho de tenacidade e especialmente na maior resistência à iniciação de trincas (iniciação) de fadiga. Vale salientar que, é uma prática da indústria automobilística a utilização de soldagem externa, tal como foi adotada no presente estudo.

Ademais, Silva et al. [12] argumenta que, com a ausência dos elementos níquel e manganês, em relação ao consumível sólido, permite ao material avançar menos no campo austenítico durante o processo de soldagem, evitando a formação de microestruturas indesejáveis, destacando-se para a possibilidade de geração de fases martensíticas frágeis nos contornos de grão austeníticos remanescentes durante o resfriamento rápido da junta soldada. Esses mesmos resultados foram identificados neste estudo.

Outro aspecto a se destacar, de acordo com ESAB [I3] é que a utilização do metal de adição AISI 439Ti produz baixíssimo nível de respingos e se adapta bem a juntas com folgas pronunciadas devido a geometria do cordão de solda. Tais respingos na região da solda, que notoriamente constituem pontos de iniciação de trincas por fadiga, levariam ao material a apresentar menor vida em fadiga. Essas características foram observadas nos conjuntos confeccionados para este estudo.

A corrosão intergranular ocorreu ao se utilizar dois metais de adição (arame tubular e sólido), mesmo com o menor aporte térmico oriundo do processo com uso do arame tubular. Considerando-se que o estabilizador (titânio) é igual para os aços inoxidáveis AISI 409 e 439, esse deve ser fator principal que levou à sensitização na ZTA. Por consequência esta condição explica porque a ZTA foi o local onde foram identificadas as falhas de fadiga nos testes.

Os resultados obtidos neste estudo corroboram com o estudo de Lakshminarayanan e Balasubramanian [5], que identificou que a exposição à temperatura na faixa entre $500^{\circ} \mathrm{Ce} 900^{\circ} \mathrm{C}$ leva à precipitação de carbonetos ricos em cromo diretamente associados à sensibilização em aços inoxidáveis. Uma vez que a formação de carbonetos ricos em cromo acompanha a difusão de átomos deste elemento para os contornos de grão, o menor tempo de exposição às temperaturas de sensibilização reduz a quantidade de carbonetos ricos em cromo formados nesses contornos.

Adicionalmente, os resultados obtidos por Kotecki e Armao [14] também foram obtidos neste estudo, ou seja, como a maior parte do carbono é encontrada perto dos contornos de grão, a formação de carboneto de cromo remove um pouco de cromo da solução perto desses contornos, reduzindo assim a resistência à corrosão dessas áreas localizadas.

Modenesi et al. [15] destaca que 0 aço inoxidável AISI 409, em geral, pode ser soldado de maneira a se obter propriedades adequadas. Por outro lado, os aços AISI 430, 442 e 446 , que apresentam teores de cromo mais elevados, apresentam maior sensibilidade a problemas de fragilização durante a soldagem e, por consequência, à incidência de corrosão intergranular. Tais afirmações foram corroboradas neste estudo, onde os corpos de prova foram produzidos com aço inoxidável 439 e todos apresentaram corrosão intergranular.

Em um trabalho paralelo, os presentes autores avaliaram a condição de soldagem praticada na parte interna dos tubos, considerando a combinação da amostra soldada com tubo de aço inoxidável AISI 409 e metal de adição na forma de arame sólido. Nesta situação foram obtidos melhores resultados, em comparação com a soldagem externa. Infelizmente, os presentes autores não conseguiram acesso a estudos similares de avaliação da condição de soldagem interna, considerando-se que esta posição apresenta distribuição de tensões mais adequada para a aplicação. Este tema deverá ser trato num estudo posterior.

\section{CONCLUSÃO}

Os resultados obtidos demonstraram a maior eficiência do tubo de aço inoxidável AISI 409 em comparação ao tubo de aço inoxidável 439, para todas as condições de uso avaliadas. Além disso, o arame tubular AISI 439Ti apresentou comportamento superior em relação ao do arame sólido AISI 307Si, justificando sua utilização como melhor opção para metal de adição.

As juntas obtidas com o arame tubular são executadas mais rapidamente e apresentaram uma durabilidade maior que a junta de arame sólido após a realização de ensaios de fadiga, posteriores ou não a carregamentos de fadiga térmica.

Portanto, a partir deste estudo, pode-se recomendar às empresas do setor automotivo, que elas efetuem a soldagem externa do tubo de aço inoxidável 409 em combinação com metal de adição na forma de arame tubular, pois esta constitui a melhor opção de combinação para a produção de escapamentos de veículos leves. O método de soldagem externa corrobora a prática mais utilizada pela indústria automobilística de soldagem de tubo de aço inoxidável e flange.

\section{REFERÊNCIAS}

I Singh MK. Application of steel in automotive industry. International Journal of Emerging Technology and Advanced Engineering. 2016:246-253.

2 Aniekan El, Ejiroghene KO, Gobir A. Engineering material selection for automotive exhaust systems using CES software. International Journal of Engineering Technologies. 2016;50-60. 
Silva et al.

3 Silva FL. Comportamento em corrosão sob tensão de uma junta soldada de aço inoxidável ferrítico ABNT 439 soldado com adição de aço inoxidável austenítico ABNT 309 em meios contendo cloretos (tese). Ouro Preto: Programa de Pós-graduação em Engenharia de Materiais, REDEMAT, 2017.

$4 \mathrm{Chiu} \mathrm{H}$. Creep behavior of $409 \mathrm{~L}$ and 436 ferritic stainless steels applied for automotive exhaust system. Mechanics of Materials. 2013;302:252-257.

5 Lakshminarayanan AK, Balasubramanian V. Sensitization resistance of friction stir welded AISI 409 M grade ferritic stainless steel joints. International Journal of Advanced Manufacturing Technology. 2012;•••:96I-967.

6 Cunha HM. Caracterização de juntas soldadas de aços carbono inoxidáveis utilizando arame AWS E309L TI-I [trabalho de conclusão de curso]. Ilha Solteira: Universidade Estadual Paulista; 2016.

7 Gerdau. Aços planos Gerdau. São Paulo: Gerdau; 2014 [acesso em 30 jul. 2018]. Disponível em: http://www.acobril. com.br/wp-content/uploads/2014/01/catalogo-acos-planos-gerdau.pdf

8 ASTM International. EI I 2- 13: Standard Test Methods for Determining Average Grain Size. West Conshohocken: ASTM International; 2013.

9 ASTM International. A763-93: Standard Practices for Detecting Susceptibility to Intergranular Attack in Ferritic Stainless Steels. West Conshohocken: ASTM International; 2009.

10 Gonçalves GF. Análise da sensitização de juntas soldadas em aço inoxidável ferrítico com solda de arame tubular monoestabilizado e biestabilizado ao nióbio e titânio [Trabalho de IC]. São Caetano do Sul: Engenharia Mecânica, Centro Universitário, Instituto Mauá de Tecnologia; 2016.

I Rabbi MS. Fadiga dos metais. Módulo 4. In: Morais WA, Magnabosco AS, Netto EBM. Metalurgia física e mecânica aplicada. 2. ed. São Paulo: ABM; 2009. cap. 2, p. 4I5-438.

12 Silva FS, Castilho J, Morais WA. Desempenho em fadiga de uma junta soldada dissimilar de aço carbono e aço inoxidável 409 obtida através de arame de solda tubular e sólido. Unisanta Science and Technology; 20 I8;7(I): 1417.

13 ESAB. Catálogo de Produtos ESAB Segmento Transporte. 2018 [acesso em 20 out. 20 I8]. Disponível em: http:// www.esab.com.br/br/pt/support/documentation/upload/catalogo-automotivo-preview.pdf

I4 Kotecki D, Armao F. Stainless steel: welding guide. Ohio: The Lincoln Electric Company; 2003.

I5 Modenesi PJ, Marques PV, Santos DB. Metalurgia da soldagem. Belo Horizonte: UFMG; 2012.

Recebido em: 19 Fev. 2019

Aceito em: 16 Fev. 2020 